\title{
Combining Biosensing Technology and Virtual Environments for Improved Urban Planning
}

\author{
Gl_Forum 2018, Issue.1 \\ Page: 344 - 357 \\ Full Paper \\ Corresponding Author: \\ bernd.resch@sbg.ac.at \\ DOI: 10.1553/giscience2018_01_s344
}

\author{
Peter Zeile' and Bernd Resch ${ }^{2}$ \\ 'Karlsruhe Institute of Technology KIT, Germany \\ 2University of Salzburg, Austria
}

\begin{abstract}
The Urban Emotions initiative uses biosensing technology to determine how people feel in the city, which is of particular relevance for architecture and urban planning. While past experiments focused more on pedestrian or bicycle traffic, accessibility and wayfinding, this paper proposes the use of virtual models as a basis for human sensorial measurement. Virtual space offers the possibility of minimizing external (environmental) influences to focus on the evaluation of design impressions. Inspiration for the method was ' $Q$-sorting' according to Stephenson (1953) and, in the context of urban planning, Krause (1974). Virtual models of real situations are used to determine whether test participants respond positively or negatively to the architecture or their environment. $360^{\circ}$ videos, virtual reality ambience and VR glasses are used as output devices. In this virtual environment, it is possible to create standardized, comparable laboratory situations allowing researchers to draw more reliable and focused conclusions about human responses to their physical environment. The challenge for the future will be to transfer this knowledge of citizens' responses to the built environment into real design processes.
\end{abstract}

\section{Keywords:}

urban planning, sensor technology, physiological sensing, virtual reality, perception

\section{Introduction}

Digitization is dramatically changing societies through developments in data acquisition processes, accessibility to information and, potentially, greater transparency with respect to information quality. Thanks to social networks and blogging, the barrier to posting opinions and impressions online is relatively low. In consequence, we are also experiencing increased interest in public participation processes, although these have yet to be adequately implemented in practice (Streich, 2014, 137). However, current urban planning and design practice is traditionally dominated by the same groups of stakeholders, while others are still excluded from digital information, despite inclusive planning practices like the 'public future lab' (Petrin, 2012; Petrin \& Wildhack, 2015) and the well-accepted insight that 'urban development is a community task' (Selle, 2014). Politicians fear falling into the 'participational trap' (Wagner, 2014) - that is, they are well aware of potential adverse effects 
of public participation initiatives on their own political agenda. In many cases, urban planning processes take place in offices and behind desks. They do not meet the needs of citizens and do not take digital forms of participation into account (Brenner et al., 2012). Nevertheless, the question arises as to how we can use digital methods in the lead up to the planning process.

Some new methods, together with the rediscovery of 'old classics, digitally renovated', offer a promising toolbox for planners in this regard, with methods that aim to involve humans (digitally) in this process being of particular interest.

\section{State of research}

Jane Jacobs was one of the pioneers of a bottom-up, citizen-friendly planning approach (Jacobs, 1961), which was revolutionary in the USA at the time and is nowadays embedded legally in urban planning processes in the US as well as in many European countries. This development has given rise to the following problems and questions, as Jacobs's original approach has been adapted and integrated into the Urban Emotions initiative (Resch et al., 2015): How can all heterogeneous interests be integrated into the planning process? Are citizens' spatial perceptions measurable? Which new technological approaches can improve the planning process? The Urban Emotions initiative uses 'human sensors' (Resch, 2013) for these purposes, ranging from social media to biostatistical 'wearables' and digital participation methods. The resulting set of methods considers the city as a 'system of currents' (Castells, 1999), or as an 'organism', as Hamburg's former building director Fritz Schumacher proclaimed in the 1920s and Geoffrey West confirmed in 2017 (Fischer, 1977; West; 2017). Christian Wolfe (2017) asks whether the 'Context City' can be an alternative to the Smart City, because it looks for a new 'identity' (or even context) in a globalized world to distinguish itself from an economy-driven 'smart city'. Again, the focus is on people, because only with their help can the city act 'intelligently' and not lose its identity.

\section{Participatory sensing}

Within Participatory Sensing (Burke et al., 2006), one of the most important fields of research is 'emotional mapping', the focus of which is always on how humans perceive the natural and built environment (Downs \& Meyer, 1978). The 'Situationist International' laid the foundation for 'mental maps' based on 'psychogéographie' and 'dérive' (Debord, 1956), and Kevin Lynch used these maps as a planning aid. 'We are not simply observers of this spectacle, but are ourselves a part of it, on the stage with the other participants. Most often, our perception of the city is not sustained, but rather partial, fragmentary, mixed with other concerns. Nearly every sense is in operation, and the image is the composite of them all' (Lynch, 1960, 2). Psychologist and community worker Stefan Dinter portrays the city with the help of three pictures and a simple triangulation (Dinter, 2015). The combination of digital mapping methods to record emotions (Nold, 2009; Klettner et al., 2013) and the increasing recognition of the 'emotion approach' in scientific discourse, as well as its application in an urban context (Schöning \& Bonhage, 2015; Vernier et al., 2016), show a new acceptance of the approach as a basis for urban planning. 
Kanjo et al. (2015) present a methodological and technological overview of available affective sensor systems; Christian Nold in 'Device Studies of Participatory Sensing' (Nold, 2017) describes the future of 'participatory measurement' with newly developed environmental sensors. The use of environmental sensor data in combination with epidemiological data will be tested in the SmartAQnet project in Augsburg (Schäfer et al., 2017). As part of the Urban Emotion initiative, psychophysiological monitoring was carried out in the context of 'barrier-free planning' (Rodrigues da Silva et al., 2014; Beyel et al., 2016) and bicycle traffic (Groß et al., 2015; Groß \& Zeile 2016; Zeile et al. 2016).

\section{Virtual Reality and $360^{\circ}$ VR}

Since cities are constantly exposed to influences that themselves change, such as the weather, traffic density or crowd gatherings, the use of virtual reality is suitable for a laboratory investigation with replicable framework conditions. Although formerly available 'only' as a freely-navigable 3D city model on the computer monitor (Coors \& Zipf, 2005; Döllner et al., 2006; Zeile, 2010), models nowadays can be experienced as 'fully immersive' in a closed 3D ambience, either as a fantasy world or as an illustration of the built environment. Headmounted displays (HMDs) such as Oculus Rift or HTC Vive allow users to capture their physical activities and interact with the computer system using new input devices and tracking systems. The degree of immersion is so high that the transition between the real and the virtual worlds becomes fluid if the human visual field and the subsequent representation of the spatial environment are correctly simulated during recording (Yuhan et al., 2015; Broschart, 2017, 133ff). On the other hand, promising emotional measurement approaches in the virtual context have been explored in the gameplay Assassin's Creed (Osborne \& Jones, 2017) with monitor VR, integrating a very high level of detail.

However, the effort of creating highly detailed photorealistic 3D city models can be greater than the creation of high-end interior design models (Broschart \& Zeile, 2015), so the question arises whether a $360^{\circ} \mathrm{VR}$ image is sufficient, at least for inventorying and for simple digital manipulations of the existing real-world environments. Panoramic photographs and videos (also known as $360^{\circ}$ videos) were used to assess landscape aesthetics in the late 1990s (Bishop \& Hull, 1991; Bishop, 2005). Folz et al. (2016), whose attempts form the basis for the present paper, published their first attempts to make 3D stereo recordings ( 2 action cams and anaglyph video) and $180^{\circ}$ videos. The application was limited, however, because at the time an immersive experience was only possible via Google Cardboards or Oculus Developer Edition (DK1), and the monitor resolution was still too pixelated.

The use of spherical camera support systems with six action cameras has received little or no examination so far (January 2018) in spatial planning disciplines, such as architecture, urban planning or landscape planning. Currently, only publications on ergonomics and educational games integrate this technology (Rupp et al., 2016).

\section{Qualitative research methods}

Q-method is an innovative approach in qualitative social research to examine people's subjectivity (Müller \& Kals, 2004) and is based on the works of Stephenson (1953). It is useful for collecting complex opinions and attitudes at the interface of quantitative and 
qualitative methods. Like the Urban Emotions initiative, Q-method aims to make opinions and personal interpretations visible. Stephenson himself stated that Q-method is an approach that contrasts with traditional social research methods, which are based on testtheoretical frameworks and categorical systems (Stephenson, 1953).

Q-Sorting ('Q-sort' for short) is the best-known technique to rank variables like statements, words or images. One sorting rule is, for instance, to evaluate pictures along a scale from beautiful to appalling. Experiments should usually involve 10 to 50 test participants. The approach has its origins in research disciplines such as political opinion-forming (e.g. Thomas \& Baas, 1996), media research (Singer et al., 1996) and gender research (Febbraro, 1995), but promising results in the 'urban context' were produced by Krause (1974) in the application area of housing value analysis, the detection of residential requirements, and the classification of living environments. Lange (1999) described a potential benefit in digital landscape design, but the scientific discussion and application went no further after this date in the research field of urban and landscape planning.

In our approach, we used a simple Q-sort. Participants were required to classify virtual environments with different design proposals, for comparison with the biostatistical dataset, simply as Good or Bad.

\section{The experiment}

The framework for the experiment comprises three steps: (1) content processing, (2) combining VR ambient with biostatistical analysis, and (3) the combined VR, biosensing and Q-sorting approach. This leverages the advantages of the various approaches as a virtual urban laboratory for detecting citizens' reactions to an urban environment, excluding 'urban disturbances' such as noise, dangerous traffic conditions or changing weather conditions.

The core idea is to create a $360^{\circ}$ video of an urban environment and then to analyse the test person's physiological reactions. Measuring 'stress' along a strict timeline of events seems to produce a better comparable setting and more easily reproducible results than a track in the physical world with unforeseen incidents. Following this rationale, we defined the research questions for our experiment:

- How can a $360^{\circ}$ video be edited so that it can be used as a basis for biostatistical measurements?

- Does it make sense to perform the investigations at a fixed virtual location or are more dynamic routes also possible?

- Can the virtual route in the VR environment be measured using existing technologies? How is the route tracked virtually?

- How suitable are virtual models for Q-sorting?

In the following section, we discuss provisional answers to these questions, as well as advantages and disadvantages of the approach. 


\section{Content Processing}

As already mentioned, a key element in the experimental setup is preparing a reproducible situation that always has the same visual and auditory content. It is important to prepare urban routes in which emotions are measured as comfortably as possible.

\section{$360^{\circ}$ Videos}

For the $360^{\circ}$ videos, an Omni-Rig from GoPro was used (Figure 1). The advantages of this technology are that the array automatically synchronizes the six cameras at pixel level, and each camera delivers videos in Ultra High Definition (so-called 4K).
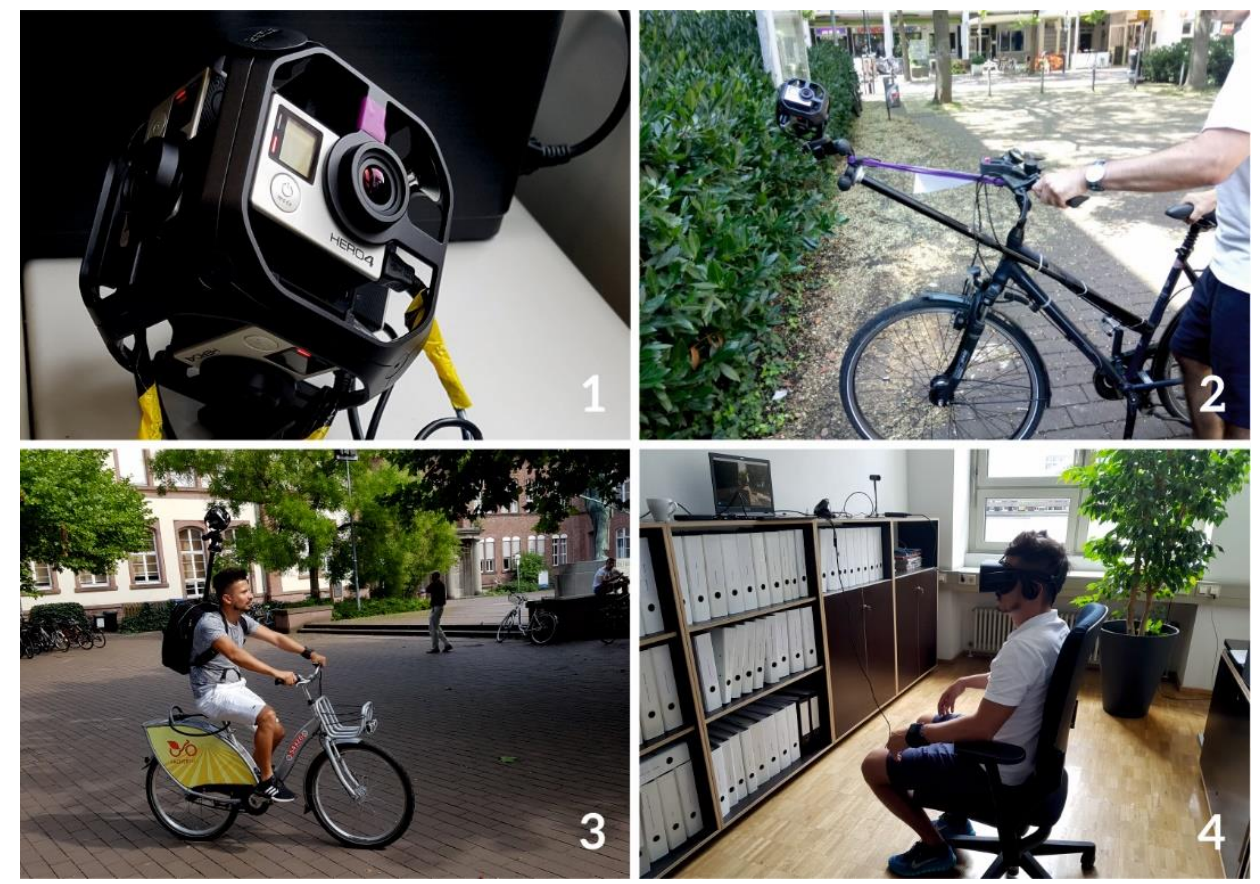

Figure 1: (1) The Omni-Rig, with its six synchronized action cams for creating spherical videos. (2) Test drives in the so-called 'cantilever mode' and (3) in the 'Streetview mode'. (4) The composite video can now be viewed on the Oculus and used as an audio-visual test environment for biostatistical monitoring.

With the system-specific stitching software Kolor, spherical $360^{\circ}$ films with a resolution of up to $8 \mathrm{~K}(7,680 \times 4,320$ pixels $)$ are possible, producing movie-quality videos. Because the movie produced has to be pre-processed and presented on a standard PC for displaying the content on the Oculus Rift headset (the VR goggle) via the GoPro VR-player, a film resolution of $3,840 \times 1,920$ pixels, transformed into MP4, has proven to be a good compromise of the highest possible quality and performance.

In order to examine whether it is possible to evaluate urban aesthetic issues using biosensors, we investigated whether the methodology from the emocycling projects (Groß et al., 2015), 
where cyclists' stress levels are measured with smartband and GPS technology, can also be applied to the virtual context. Experiments using a pedestrian perspective were deliberately omitted since no Steadicam system is available for the Omni-Rig, and because the image stabilization software did not provide the desired quality. Therefore, test drives were first performed with a camera in 'cantilever mode' (Figure 1 (2)) or in 'Streetview mode' (Figure 2). Although the backpack-mounted camera was easier to handle, the 'Cantilever' method delivered better material for the evaluation because it also recorded the face of the test person. However, for the experiment (Figure 3), the backpack $360^{\circ}$ video was used (see https://youtu.be/XA9ruQPbnEc). To avoid motion sickness, stationary videos are a suitable alternative (https://youtu.be/1BuoK1TqsK0). In this mode, time-lapse recordings are also possible.

GoPro Fusion, a newly available technology for capturing $360^{\circ}$ videos, recently came onto the market. The advantages of this technology are that only two camera streams have to be stitched, and the camera weighs only around one-sixth of the Omni-Rig. The processing time for the stitching procedure is also significantly less. Due to the construction of GoPro Fusion with just two cams instead of six, it is also possible to use a gimbal for vibration reduction. The first tests produced promising results, as shown in Figure 2. In contrast to the workflow with 6 cameras, one disadvantage of the Fusion is that a manually edited focal point and horizon stabilization are only possible for the entire video and not for different sequences within it.
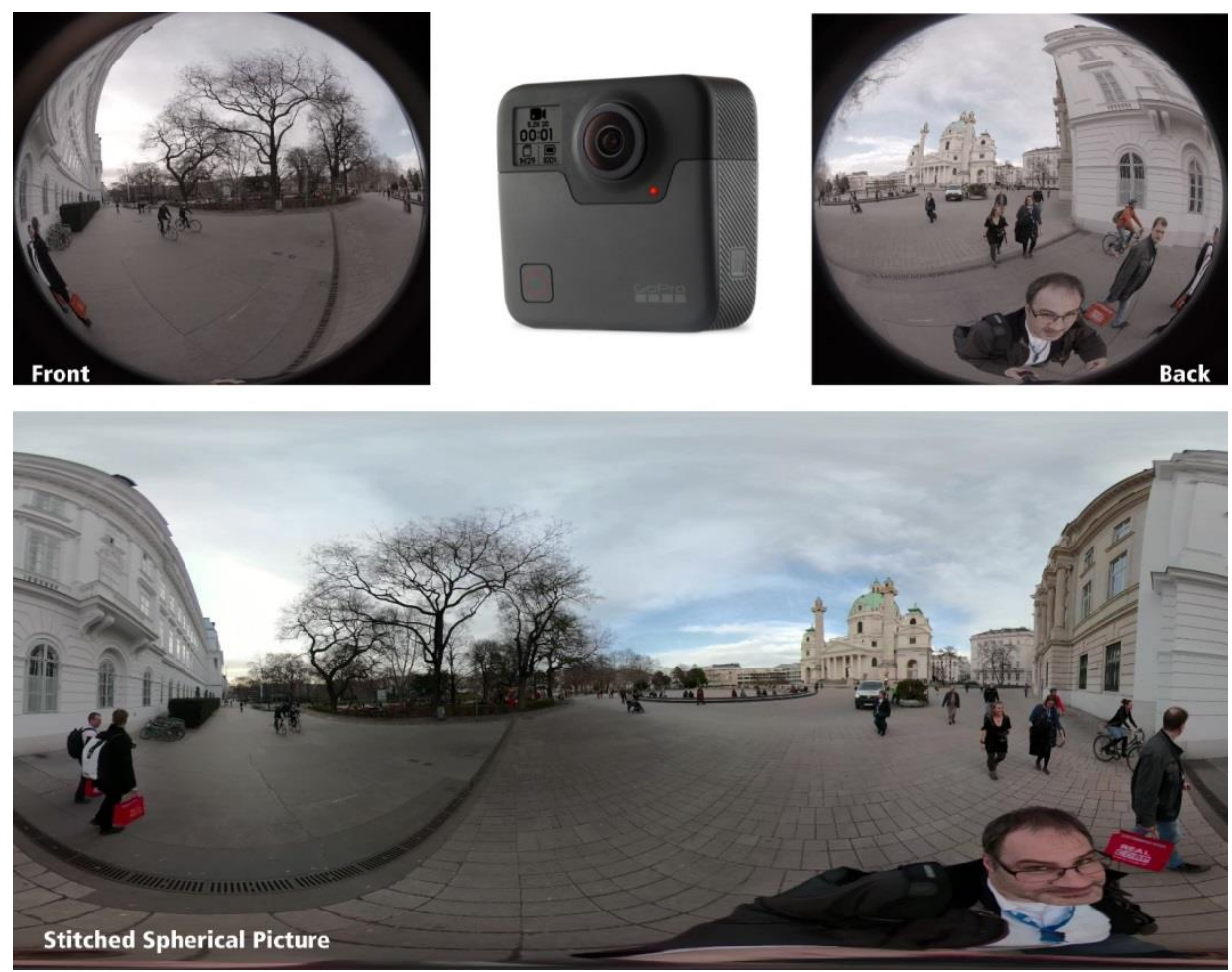

Figure 2: Creating Spehrical Pictures with just two camera streams (Front and Back). 


\section{$360^{\circ}$ Panoramas}

As a low-cost alternative in producing $360^{\circ}$ content for everybody, it is also possible to collect static pictures, which can be edited automatically to a spherical picture. As in traditional workflows using video editing software, a variety of simple pictures can be used as the footage for a video. If the editing software is able to work with spherical projection, these spherical images can be used for the creation of a $360^{\circ}$ video.
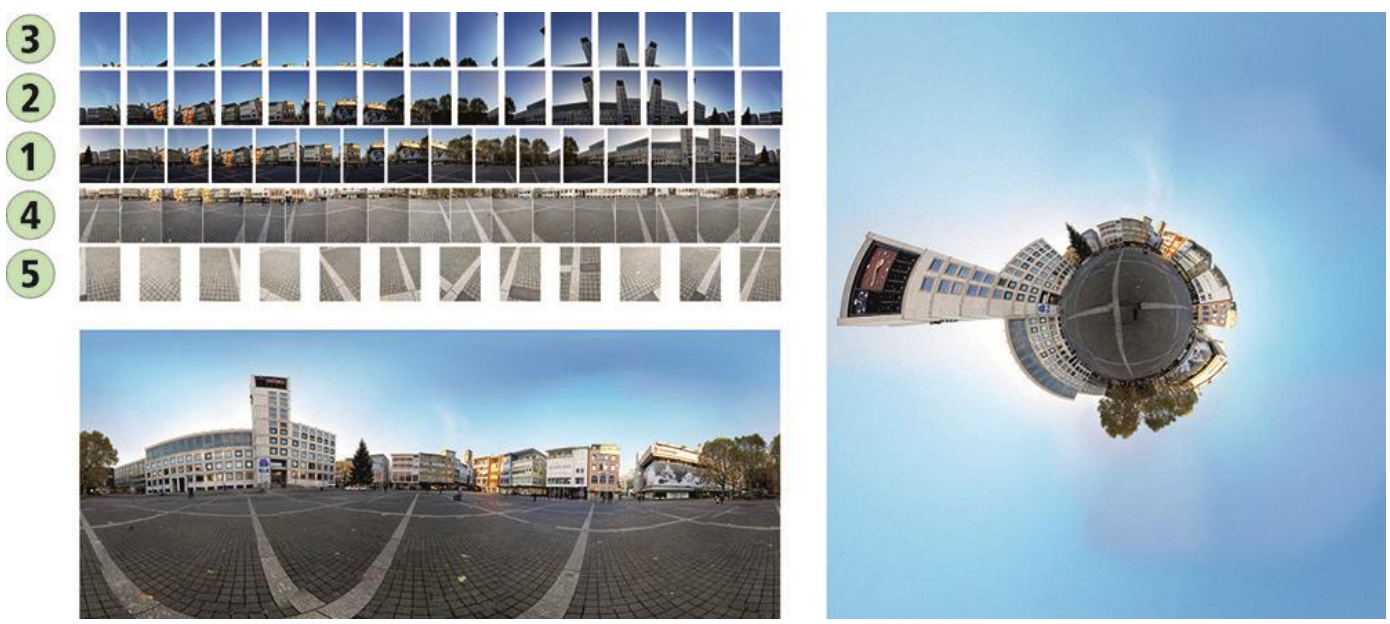

Figure 3: Recording rules for $360^{\circ}$ panoramas for post-processing in Autopano Giga. An interesting byproduct is the 'Tiny Planet' projection of the scene captured, here Marktplatz in Stuttgart.

The collection process is simple. Only 5 to 7 overlapping rows need to be photographed (see Figure 3). After that, the pictures are automatically stitched in Autopano Giga (Koehl et al., 2013) and can be saved as a panorama in a ratio of 2:1 as VR-capable image material. Using film editing software (e.g. Adobe Premiere in conjunction with the GoPro VR plugins), the production of immersive-experience films is possible. A benefit of the creation process is the possibility of generating images in 'Little Planet' or 'Tiny Planet' projection, in which the socalled 'Nadir' is the projection centre (German et al., 2007).

In search of further examples of 'good' and 'bad' architecture for a Q-sort to be measured within the experiment, a crowdsourcing campaign was launched with the aim of bringing together as many professionals and non-professionals as possible, to judge cityscapes that could then be biostatistically tested for their effects.

\section{D Models}

Both solutions presented above have the disadvantage of not allowing new projects to be integrated with the situations already captured, or only with great effort. Analysing the aesthetic impact of a new planned project is a core question in urban planning and architecture. For this use case of adding alternatives and new planning scenarios to the experiment, 3D models can also be visualized on the VR headset. A simple, smart and intuitive workflow is provided by 'Kubity' software (Bailly et al., 2015). Avoiding having to 
list a number of import and export options and having to go too deep into the possibility of drawing elements, it is possible in this workflow to work with Building Information Models (BIMs) taken from an architectural design (Petzold et al., 2015) and with common CADFiles. Due to their data structure (Brüggemann \& Both, 2015), CityGML-Models, which are very interesting for the research topic of urban perception, cannot currently be imported. In late 2017, discussion intensified about Urban Information Models (UIMs) as the 'missing link' between CityGML, IFC, BIM and GIS (Gruber \& Donaubauer, 2017), aiming to provide a sustainable exchange solution in the future.

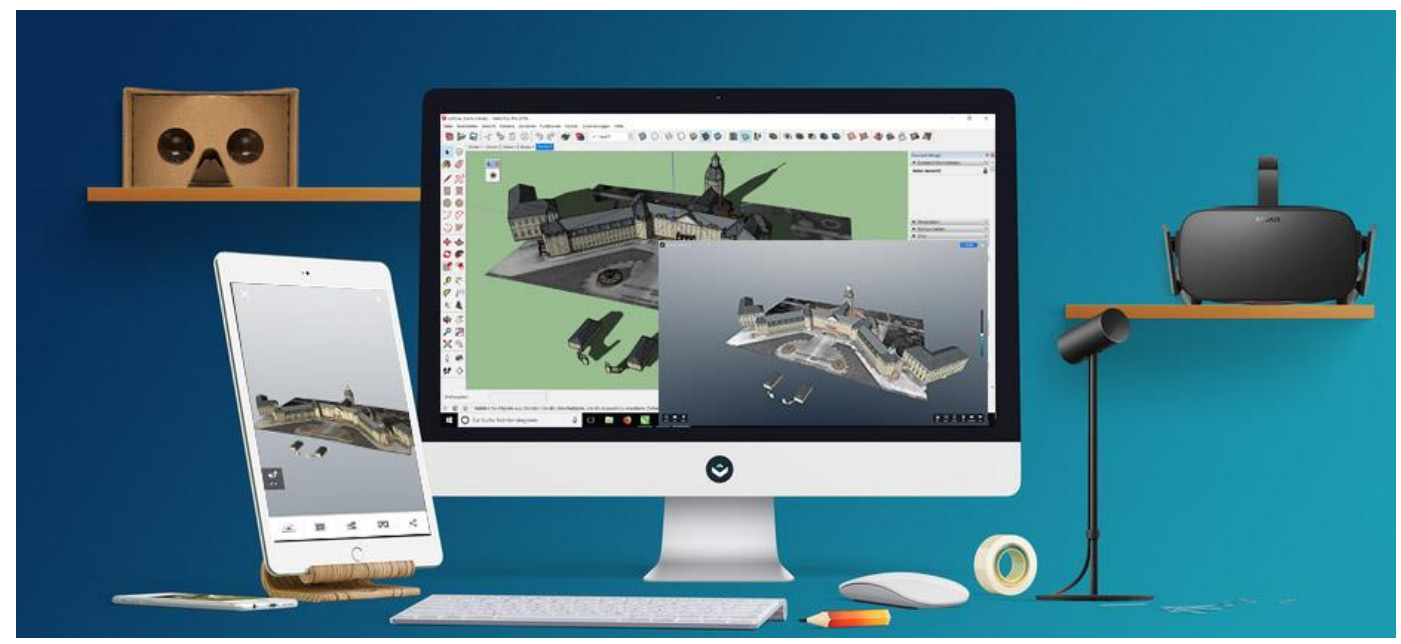

Figure 4: Kubity workflow and export options for different devices. Revit and Sketchup models can be exported to VR headsets, Cardboards and tablets, as well as to web interfaces (adapted from O'Brien, 2018).

In addition to the direct output to the VR glasses, the Kubity software offers output options useful for urban planning: a web interface, VR with the help of using Cardboards on smartphones, as well as an augmented reality solution in pedestrian perspective without Cardboards (Figure 4). However, for this experiment, we used only the VR variant. Since there is (still) no export option available for films, the models must be organized as a socalled 'tour'. The time component is consequently the same for each participant in the experiment, and therefore the results are comparable.

\section{Measuring Equipment}

The range of measuring instruments makes use of the proven combination of the Smartband body monitor, GPS tracker and GoPro Hero ActionCam (Zeile et al., 2016). The only additions are the Omni-Rig and, for the virtual ambience, the Oculus Rift Setup. 


\section{Experimental Setup}

For the preliminary investigation, the study by Núñez et al. (2017) was useful. Designed as a study to identify the comfort of road surface and infrastructure conditions, the surface condition was recorded and evaluated using smartphone accelerometers and video recordings. With the aid of the Smartband, stress peaks could be identified. In addition, we recorded the track using the GoPro Omni-Rig, adjusted and stabilized manually for the $360^{\circ}$ VR application. The choice of a small group of participants for this first investigation was deliberate: one person to wear the smartband (J1) during the Omni recording and then to ride along the virtual track (JV), and another who followed only the virtual route (PV).

\section{$4 \quad$ Results}

Psychophysiological monitoring was carried out for all routes (see Figure 5). Test person J1 rode the real-world track on their bike. Afterwards, we compared the real-world test ride (J1) with the same person's experience in virtual space - they did the tour again virtually (JV). Another test person (PV) took part only in the virtual experiment. As expected, more moments of stress (MoS) were identified in reality than in virtual mode (31 in reality (J1) vs 10 (JV) / 14 (PV) in virtual space). Both participants (JV \& PV) received a simultaneous stress trigger at only three positions in virtual space. At first glance, this seems less significant. Because participant J1 has already made the tour in the real environment, his stress triggers may be reduced. In contrast, the comparison between the reactions of test person J1 and those of the virtual cyclist (PV) identified at least nine matches. The real world test rides of $\mathrm{J} 1$ and their virtual ride (JV) yielded seven matching points.

Regardless of the results, both participants complained about nausea in the virtual environment after 15 minutes of test driving. The motion sickness on the virtual tour was more acute than expected. Because of this, the tests in motion mode were suspended.

Figure 5: Biostatistical evaluation of the runs. The real-world run (J1) with 31 moments of stress (MoS); the two recorded in the Oculus biostatistical stress moments (PV, JV); all data superimposed.

One result, after comparing video footage for all stress points, was that 'tunnel points' or 'bottlenecks' (i.e. trees close to the road) were perceived as 'stressful' moments in both reality and the virtual tour. The participant in the virtual journey had less intense stress reactions in situations where it is unclear how other road users respond. Comparing the reactions of the Virtual Driver (PV) who had no experience of the real track with those of the driver of the real track (J1), there were many similarities with regard to bottlenecks, right-of-way situations, and other road users. 


\section{Discussion and outlook}

The present setup promises great technological potential for use in spatial planning and architecture.

The advantages of the method are clearly in the fast recording of the real-world environment and consistent workflow. Furthermore, the crowdsourced examples can be easily combined with sequences from moving situations to form a film. The integration of additional content with the help of plugins is possible, while Kubity also offers the opportunity to experience virtual models in a virtual environment.

A disadvantage of the approach is that recording from a moving camera position gives rise to motion sickness. A more suitable solution for camera mounting and post-processing needs to be found. According to the manufacturer, the stabilization process has been optimized to such an extent that motion sickness no longer occurs. Nevertheless, the recommendation is currently that the pictures should be taken from a fixed camera point. As a result, the integration of the panoramas is easier.

No satisfactory solution has so far been found to allow several planning scenarios to be presented within one single tour. There is still a media break between the $360^{\circ}$ video and the virtual models. Export is possible only in video format. Playing virtual tours could be an alternative solution here.

Tracking in a virtual environment works well because the existing GPS track can be used. This makes the measurements easy to synchronize. However, for the Q-sorting experiment in virtual space, a virtual GPS track and virtual models have to run in a synchronized manner and to be clearly assigned to the situation being examined.

Meanwhile, the crowdsourcing process for Q-sorting has been started; the model collection must now be prepared, classified and reviewed for the possible or hoped-for emotional responses, and integrated into the test environment. In the future, the software Enscape will be tested as a solution for the integration of virtual models, enabling data from Revit and Sketchup to be integrated into the virtual environment. With this workaround, even live manipulation of the models is possible. In addition, the output as a $360^{\circ}$ video is integrated, so that at least a comparison of the $3 \mathrm{D}$ models on film with the existing real situations is possible. Thus Video Compositing is possible, which is reminiscent of the vintage age of photomontage, but now it can happen in a $360^{\circ}$ environment.

\section{Acknowledgements}

We would like to express our gratitude to the German Research Foundation (DFG Deutsche Forschungsgemeinschaft) and the Austrian Science Fund (FWF) for supporting the project 'Urban Emotions' (DFG reference number ZE 1018/1-1, FWF reference number I-3022). We also thank the Austrian Research Promotion Agency (FFG) for supporting the project 'Walk\&Feel' (Pr.Nr. 865208). 


\section{References}

Bailly, J.-P., Checinski, A., Romain, G., Gully, R., Jobbe-duval, H., Schoner, N., Vasseur, N. (2015).

Beyel, S., Wilhelm, J., Mueller, C., Zeile, P., \& Klein, U. (2016). Stresstest städtischer Infrastrukturen ein Experiment zur Wahrnehmung des Alters im öffentlichen Raum. In M. Schrenk, V. Popovich, P. Zeile, P. Elisei, \& C. Beyer (Eds.), REAL CORP 2016: Proceedings/Tagungsband (pp. 689_ 698). Wien. https://doi.org/10.13140/RG.2.1.1451.6721

Bishop, I. D. (Ed.). (2005). Visualization in landscape and environmental planning: Technology and applications. London: Taylor \& Francis.

Bishop, I. D., \& Hull, B. R. (1991). Integrating technologies for visual resource management. Journal of Environmental Management, 32(4), 295-312. https://doi.org/10.1016/S0301-4797(05)80068-4

Brenner, N., Marcuse, P., \& Mayer, M. (Eds.). (2012). Cities for people, not for profit: Critical urban theory and the right to the city. London: Routledge. Retrieved from http://site.ebrary.com/lib/uniregensburg/Doc?id=10610152

Broschart, D. (2017). Mobile Geoweb-Methoden für die Planung - Die Fortentwicklung des stadtund umweltplanerischen Methodenrepertoires im Rahmen von Crowdsourcing, Monitoring und Echtzeitplanung. Retrieved from https://kluedo.ub.unikl.de/files/5078/_2017_Broschart_Diss_kluedo.pdf

Broschart, D., \& Zeile, P. (2015). ARchitecture: Augmented Reality in Architecture and Urban Planning. In E. Buhmann, S. M. Ervin, \& M. Pietsch (Eds.), Peer Reviewed Proceedings of Digital Landscape Architecture 2015: at Anhalt University of Applied Sciences (pp. 111-118). Berlin, Offenbach: Herbert Wichmann Verlag, VDE Verlag GmbH.

Brüggemann, T., \& Both, P. von. (2015). 3D-Stadtmodellierung: CityGML. In A. Borrmann, M. König, C. Koch, \& J. Beetz (Eds.), VDI-Buch. Building Information Modeling: Technologische Grundlagen und industrielle Praxis (pp. 177-192). Wiesbaden: Springer Vieweg. https://doi.org/10.1007/978-3-658-05606-3_10

Burke, J., Estrin, D., Hansen, M., Parker, A., Ramanathan, N., Reddy, S., \& Srivastava, M. (2006). Participatory sensing. World Sensor Web 2006 Proceedings, 1-5.

Castells, M. (1999). The power of identity (Reprinted.). The information age: economy, society and culture / Manuel Castells ; Vol. 2. Cambridge, Mass.: Blackwell.

Coors, V., \& Zipf, A. (Eds.). (2005). 3D-Geoinformationssysteme: Grundlagen und Anwendungen. Heidelberg: Wichmann.

Debord, G. (1956). Theorie de la dérive. Les Lèvres Nues. (9).

Dinter, S. (2015). Karlsruhe. Eine Stadt erleben: Fotografien (1. Aufl.). Lindemanns Bibliothek: Bd. 234. Bretten: INFO Verlag.

Döllner, J., Kolbe, T. H., Liecke, F., Sgouros, T., \& Teichmann, K. (2006). The virtual 3d city model of Berlin: Managing, integrating, and communicating complex urban information. In Proceedings of the 25th International Symposium on Urban Data Management. Aalborg.

Downs, R. M., \& Meyer, J. T. (1978). Geography and the Mind: An Exploration of Perceptual Geography. American Behavioral Scientist, 22(1), 59-77. https://doi.org/10.1177/000276427802200104

Febbraro, A. R. (1995). On the epistemology, metatheory, and ideology of Q methodology: A critical analysis. Trends and issues in theoretical psychology, 144-150.

Fischer, M. F. (1977). Fritz Schumacher, das Hamburger Stadtbild und die Denkmalpflege. Arbeitshefte zur Denkmalpflege in Hamburg: Vol. 4. Hamburg: Christians.

Folz, S., Broschart, D., \& Zeile, P. (2016). Raumerfassung und Raumwahrnehmung - aktuelle Techniken und potenzielle Einsatzgebiete in der Raumplanung. In M. Schrenk, V. Popovich, P. Zeile, P. Elisei, \& C. Beyer (Eds.), REAL CORP 2016: Proceedings/Tagungsband (pp. 541-550). Wien. https://doi.org/10.13140/RG.2.1.3983.7683 
German, D. M., Burchill, L., Duret-Lutz, A., Pérez-Duarte, S., Pérez-Duarte, E., \& Sommers, J. (2007). Flattening the viewable sphere. In Proceedings of Computational Aesthetics 2007. https://doi.org/10.2312/COMPAESTH/COMPAESTH07/023-028

Groß, D., Holderle, C., \& Wilhelm, J. (2015). EmoCycling -Analyse von Radwegen mittels Humansensorik für Kommunen. In M. Schrenk, V. Popovich, P. Zeile, \& P. Elisei (Eds.), REAL CORP 2015: Proceedings/Tagungsband (pp. 249-259). Wien, Ghent: CORP - Competence Center of Urban and Regional Plan. Retrieved from http://conference.corp.at/archive/CORP2015_118.pdf

Groß, D., \& Zeile, P. (2016). EmoCyclingConcept - Potenziale der emotionalen Stadtkartierung. In J. Strobl, B. Zagel, G. Griesebner, \& T. Blaschke (Eds.), AGIT: Journal für Angewandte Geoinformatik (Vol. 2, pp. 273-278). Berlin, Offenbach: Wichmann Verlag. https://doi.org/10.14627/537622040

Gruber, U., \& Donaubauer, A. (2017). BIM und GIS Interoperabilität: Datenformate, Standards, Integrationsmöglichkeiten. In R. Kaden, C. Clemen, R. Seuß, J. Blankenbach, R. Becker, A. Eichhorn, et al.; RunderTisch GIS, DVW (Eds.), Leitfaden Geodäsie und BIM (pp. 49-68). DVW; Runder Tisch GIS e.V.

Jacobs, J. (1961). The death and life of great american cities. New York: Random House Vintage Books.

Kanjo, E., Al-Husain, L., \& Chamberlain, A. (2015). Emotions in context: Examining pervasive affective sensing systems, applications, and analyses. Personal and Ubiquitous Computing. Advance online publication. https://doi.org/10.1007/s00779-015-0842-3

Klettner, S., Huang, H., Schmidt, M., \& Gartner, G. (2013). Crowdsourcing affective responses to space. Kartographische Nachrichten, 2013(2), 66-72.

Koehl, M., Schneider, A., Fritsch, E., Fritsch, F., Rachedi, A., \& Guillemin, S. (2013). Documentation of historical building via virtual tour:: the complex building of baths in Strasbourg. ISPRS International Archives of the Photogrammetry, Remote Sensing and Spatial Information Sciences, XL-5/W2, 385-390. https://doi.org/10.5194/isprsarchives-XL-5-W2-385-2013

Krause, K.-J. (1974). Stadtgestalt und Stadterneuerung. Bonn: Bundesvereinigung Deutscher Heimstätten e.V.

Lange, E. (1999). Realität und computergestützte visuelle Simulation. Zugl.: Zürich, ETH, Diss., 1998. ORL-Bericht: Vol. 106. Zürich: vdf Hochschulverl.

Lynch, K. (1960). The image of the city. Publication of the Joint Center for Urban Studies. Cambridge Mass. u.a.: MIT Press.

Müller, F. H., \& Kals, E. (2004). Q-Sort Technique and Q-Methodology-Innovative Methods for Examining Attitudes and Opinions. Forum Qualitative Sozialforschung / Forum: Qualitative Social Research, 5(2). Retrieved from http://www.qualitativeresearch.net/index.php/fqs/article/download/600/1302

Nold, C. (2009). Emotional cartography: Technologies of the self. Retrieved from http://emotionalcartography.net

Nold, C. (2017). Device Studies of Participatory Sensing: Ontological Politics and Design Interventions. Thesis / Dissertation. London.

Núñez Javier Y. M., \& Rodrigues da Silva, A. N. (2017). Assessment using smartphone sensors and a geographic information system. In Proceedings of CUPUM2017. Adelaide.

Núñez Javier Y. M., Zeile, P., \& Rodrigues da Silva, A. N. (2017). Management of infrastructure for cycling transportation systems using smart sensors. Future Cities - Research for a Sustainable Urban Development, Annweiler.

O`Brien, R. (2018). Kubity | SketchUcation. Retrieved from https://sketchucation.com/kubity-forsketchup

Osborne, T., \& Jones, P. I. (2017). Biosensing and geography: A mixed methods approach. Applied Geography, 87, 160-169. https://doi.org/10.1016/j.apgeog.2017.08.006 
Petrin, J. (2012). Nexthamburg: Bürgervisionen für eine neue Stadt. Hamburg: Ed. Körber-Stiftung.

Petrin, J., \& Wildhack, A. (2015). Ein Inkubator für Bürgerprojekte: Stadtmacher erprobt einen neuen Ansatz der nutzergenerierten Stadtentwicklung. Planerin. (3), 25-27.

Petzold, F., Hild, A., Langenhan, C., \& Thomä, H. (2015). BIM im architektonischen Entwurf. In A. Borrmann, M. König, C. Koch, \& J. Beetz (Eds.), VDI-Buch. Building Information Modeling: Technologische Grundlagen und industrielle Praxis. Wiesbaden: Springer Vieweg.

Resch, B. (2013) People as Sensors and Collective Sensing - Contextual Observations Complementing Geo-Sensor Network Measurements. In: Krisp, J. (2013) Advances in Location-Based Services, ISBN 978-3-642-34202-8, Springer, Berlin Heidelberg, pp. 391-406.

Resch, B., Summa, A., Sagl, G., Zeile, P. and Exner, J.-P. (2015). Urban Emotions - Geo-semantic Emotion Extraction from Technical Sensors, Human Sensors and Crowdsourced Data. In: Gartner, G. and Haosheng Huang (eds.) (2015) Progress in Location-Based Services 2014, Springer International Publishing, Switzerland, pp. 199-212.

Rodrigues da Silva, A. N., Zeile, P., Aguiar, Fabiola de Oliveira, Papastefanou, G., \& Bergner, B. S. (2014). Smart sensoring and barrier free planning - project outcomes and recent developments. In N. N. Pinto, J. A. Tenedório, A. P. Antunes, \& J. R. Cladera (Eds.), Technologies for Urban and Spatial Planning: Virtual Cities and Territories (pp. 93-112). Hershey PA: IGI Global. Retrieved from http://www.igi-global.com/chapter/smart-sensoring-and-barrier-free-planning/104212

Rupp, M. A., Kozachuk, J., Michaelis, J. R., Odette, K. L., Smither, J. A., \& McConnell, D. S. (2016). The effects of immersiveness and future VR expectations on subjective experiences during an educational $360^{\circ}$ video. Proceedings of the Human Factors and Ergonomics Society Annual Meeting, 60(1), 2108-2112. https://doi.org/10.1177/1541931213601477

Schäfer, K., Emeis, S., Budde, M., Beigl, M., Cyrys, J., Schnelle-Kreis, J.,. . . Gratza, T. (2017). SmartAQnet: Remote and in-situ sensing of urban air quality. In A. Comerón, E. I. Kassianov, \& K. Schäfer (Eds.), Remote Sensing of Clouds and the Atmosphere XXII (p. 12). SPIE. https://doi.org/10.1117/12.2282698

Schöning, J., \& Bonhage, C. E. (2015). On the Acquisition of Human Emotions in Space and Time.

Selle, K. (2014). Über Bürgerbeteiligung hinaus: Stadtentwicklung als Gemeinschaftsaufgabe? ; Analysen und Konzepte (2. Aufl.). Edition Stadt/Entwicklung. Lemgo: Rohn.

Singer, J. B., Craig, D., Allen, C. W., Whitehouse, V., Dimitrova, A., \& Sanders, K. P. (1996). Attitudes of Professors and Students about New Media Technology. Journalism \& Mass Communication Educator, 51(2), 36-45. https://doi.org/10.1177/107769589605100205

Stephenson, W. (1953). The Study of Behavior: Q-technique and Its Methodology. Midway reprint series: University of Chicago Press. Retrieved from https://books.google.de/books?id=cbYLPQAACAAJ

Streich, B. (2014). Subversive Stadtplanung. Wiesbaden: Springer VS.

Thomas, D. B., \& Baas, L. R. (1996). The Postelection Campaign: Competing Constructions of the Clinton Victory in 1992. The Journal of Politics, 58(2), 309-331. https://doi.org/10.2307/296022

Vernier, M., Farinosi, M., \& Foresti, G. L. (2016). A Smart Visual Information Tool for Situational Awareness. In N. Magnenat-Thalmann, P. Richard, L. Linsen, A. Telea, S. Battiato, F. Imai, \& J. Braz (Eds.), VISIGRAPP 2016: Proceedings of the 11th Joint Conference on Computer Vision, Imaging and Computer Graphics Theory and Applications (pp. 236-245). Setúbal: SCITEPRESS. https://doi.org/10.5220/0005680402360245

Wagner, T. (2014). Die Mitmachfalle: Bürgerbeteiligung als Herrschaftsinstrument (2., unveränderte Aufl.). Neue kleine Bibliothek: Vol. 193. Köln: PapyRossa-Verl.

West, G. (2017). Scale: The universal laws of growth, innovation, sustainability, and the pace of life in organisms, cities, economies, and companies. New York: Penguin Press.

Wolfe, C. R. (2017). Seeing the Better City: How to Explore, Observe, and Improve Urban Space: Island Press. 
Yuhan, S., Lange, E., \& Thwaites, K. (2015). Improved Photographic Representation of Human Vision for Landscape Assessment. In E. Buhmann, S. M. Ervin, \& M. Pietsch (Eds.), Peer Reviewed Proceedings of Digital Landscape Architecture 2015: at Anhalt University of Applied Sciences (pp. 90-100). Berlin, Offenbach: Herbert Wichmann Verlag, VDE Verlag GmbH.

Zeile, P. (2010). Echtzeitplanung: Die Fortentwicklung der Simulations- und Visualisierungsmethoden für die städtebauliche Gestaltungsplanung. Dissertation. Retrieved from http://kluedo.ub.unikl.de/volltexte/2010/2497/index.html

Zeile, P., Resch, B., Loidl, M., Petutschnig, A., \& Dörrzapf, L. (2016). Urban Emotions and Cycling Experience - enriching traffic planning for cyclists with human sensor data. In A. Car, T. Jekel, J. Strobl, \& G. Griesebner (Eds.), GI_Forum 2016: Journal for Geographic Information Science (Vol. 1, pp. 204-216). Wien: Verlag der Österreichischen Akademie der Wissenschaften. https://doi.org/10.1553/giscience2016_01_s204 